\title{
Predicting poor prognosis in COPD patients: looking for a lamp lit in the darkness of the night
}

\author{
Ernesto Crisafulli
}

Affiliations: Cardio-Thoracic Dept, Pneumology and Respiratory Intensive Care Unit, "Carlo Poma" Hospital, Mantova, Italy.

Correspondence: Ernesto Crisafulli, Cardio-Thoracic Dept, Pneumology and Respiratory Intensive Care Unit, "Carlo Poma" Hospital, Strada Lago Paiolo 10, 46100 Mantova, Italy. E-mail: ecrisafulliapneumonet.it

@ERSpublications

Night-time dyspnoea is a prevalent and relevant symptom predicting poor prognosis in COPD patients http://ow.ly/v7aQI

"It was invisible, buried in the mud. I only saw it because I was looking for it."

"What! You expected to find it?"

"I thought it not unlikely."

Conan Doyle [1]

The other half of our life - and the better half of our life - is the night-time [2]. In the natural history of many chronic clinical conditions, we often do not think about the night as the other half of a patient's life, and the influence it has on the biological and clinical progression of disease. Moreover, night-related respiratory disease is often synonymous with the functional aspects associated with quality of sleep, arousals and apnoic events; rarely do we consider the night-time as a period of onset of specific symptoms, for example, dyspnoea in patients with chronic obstructive pulmonary disease (COPD). Even the current Global Initiative for Chronic Obstructive Lung Disease (GOLD) guidelines for COPD do not define a standard and joint approach for the diagnosis and management of nocturnal problems when staging and recommending follow-up of patients with stable disease [3]. Recently, in a meeting focussing on the nighttime symptoms and sleep disturbances of COPD patients, a panel of experts reported the poor interest in clinical studies on these aspects; moreover, the possibility of exploring the potential links between symptoms occurring during the night and the long-term clinical outcomes may demonstrate the necessity highlighting some of the clinical and unexplored aspects of COPD [4].

In this issue of the European Respiratory Journal (ERJ), LANGE et al. [5] respond to these scientific demands by presenting a study that recruited stable COPD patients from two national registries in Denmark (the Copenhagen City Heart Study (CCHS) and the Copenhagen General Population Study (CGPS)). Using an extensive questionnaire concerning patient lifestyle and health topics, they investigated the real prevalence of dyspnoea occurrence during the night. The authors also evaluated the implication of night symptoms on the long-term clinical outcomes and prognosis of stable COPD patients. In particular, they focused on exacerbation events (defined by an increase of rescue medication), hospital admissions due to an exacerbation, and all-cause mortality.

Although the study does not provide an objective measurement of nocturnal saturation (it has been proven that nocturnal hypoxaemia in COPD patients is associated with the development of adverse sequelae [6]) and the topic has previously been explored by OMACHI et al. [7] with similar findings, the paper by LANGE

Received: March 092014 | Accepted: March 102014

Conflict of interest: None declared.

Copyright @ERS 2014 
et al. [5] is clinically relevant because they prospectively examined a very large cohort of COPD patients $(\geqslant 6000)$ recruited from a real-life population source, with a very long follow-up ( $\geqslant 8$ years). There a number of key messages. First, the prevalence of night-time dyspnoea is high, representing about $4 \%$ of the total cohort of COPD patients, increasing to $9 \%$ and $16 \%$ in severe and very severe patients, respectively. As expected, this result confirms that night-time dyspnoea is a "common" symptom in stable COPD patients, and is often unnoticed by physicians and/or not reported by patients themselves [4]. For this reason, we need to develop specific measurement instruments, such as questionnaires, which identify COPD patients' perception of breathing during the night. Regrettably, to date no validated questionnaires are available.

Secondly, night-time dyspnoea is a prevalent symptom with a very relevant impact on adverse outcomes; in comparison with non-nocturnal symptomatic COPD patients (reference), nocturnal symptomatic COPD patients have a 2.3-fold higher risk of suffering a future exacerbation. Moreover, the risks of hospital admission due to an exacerbation or of dying from any cause are 3.2-fold and 1.7-fold, respectively. In other words, it is confirmed that COPD patients waking at night due to dyspnoea have a worse long-term prognosis of frequent events occurring in later life, which certainly have an impact upon the natural history of disease [3].

Thirdly, there are strong relationships between night-time dyspnoea and pulmonary and extrapulmonary clinical variables that commonly define the chronic severity/complexity of COPD and that influence the prognosis of patients [3, 6, 8-10]. In particular, the study by LANGE et al. [5] has shown that COPD patients presenting night-time dyspnoea had greater pulmonary impairment (both old and new GOLD guidelines) [3], worse baseline perceived dyspnoea (measured using the Medical Research Council (MRC) score) [8], peripheral hypoxigenation [6], an increase in events due to exacerbations [10], and the presence of current wheezing, chronic mucus hypersecretion, and some heart comorbidities like ischemic heart disease [9] and atrial fibrillation.

This raises a question: in the future management of patients with COPD, should we consider night-time dyspnoea as a new measure of severity and disease progression? And, in relation to these considerations and the knowledge that diurnal dyspnoea is a good predictor of mortality in stable COPD patients [8] (although in perceived dyspnoea there is a high degree of variability throughout the day [11]), why should we be surprised that the presence of nocturnal dyspnoea changes the prognosis of COPD patients? This result was not unlikely to be found; however, the authors found it because they were looking for it!

But "I know that I know nothing" [12]. The study by LANGe et al. [5] opens two important unknown aspects of the disease, which are of potential relevance. Recent highlights $[13,14]$ state that in COPD, some relevant attributes (single or combined multidimensional clusters [15]) that describe the differences between patients and are related to clinically meaningful outcomes, such as disease progression or death, may allow the characterisation of clinical phenotypes. In this context, patients with a high susceptibility to exacerbations, and who actually experience frequent exacerbation episodes [10], patients with a low body weight and impaired body composition [16], patients with a poor exercise capacity [17] and patients with an increased baseline diurnal functional dyspnoea [8], represent specific clinical COPD phenotypes. Considering the important implications that night-time dyspnoea has on a patient's prognosis, should we now reconsider the subpopulation of patients with night symptoms as having a new phenotype of COPD? They could be labelled "COPD symptomatic at night"? Moreover, while some COPD phenotypes related to single risk factors are susceptible to pharmacological (bronchodilators and/or inhaled steroids, nutritional support) or nonpharmacological treatment (physical exercise) and are potentially changeable, should we consider those who are "COPD symptomatic at night" to be patients in whom we can do something else? All in all, plenty of future challenges to explore!

\section{References}

Conan Doyle A. Silver Blaze. In: The Memoirs of Sherlock Holmes. London, George Newnes Ltd, 1894. von Goethe JW. Wilhelm Meister's Apprenticeship. Berlin, Johann Friedrich Unger, 1795.

Vestbo J, Hurd SS, Agustí AG, et al. Global strategy for the diagnosis, management, and prevention of chronic obstructive pulmonary disease: GOLD executive summary. Am J Respir Crit Care Med 2013; 187: 347-365.

4 Agusti A, Hedner J, Marin JM, et al. Night-time symptoms: a forgotten dimension of COPD. Eur Respir Rev 2011; 20: 183-194.

5 Lange P, Marott JL, Vestbo J, et al. Prevalence of night-time dyspnoea in COPD and its implications for prognosis. Eur Respir J 2014; 43: 1590-1598.

6 Kent BD, Mitchell PD, McNicholas WT. Hypoxemia in patients with COPD: cause, effects, and disease progression. Int J Chron Obstruct Pulmon Dis 2011; 6: 199-208.

7 Omachi TA, Blanc PD, Claman DM, et al. Disturbed sleep among COPD patients is longitudinally associated with mortality and adverse COPD outcomes. Sleep Med 2012; 13: 476-483.

8 Nishimura K, Izumi T, Tsukino M, et al. Dyspnea is a better predictor of 5-year survival than airway obstruction in patients with COPD. Chest 2002; 121: 1434-1440. 
Williams MC, Murchison JT, Edwards LD, et al. Coronary artery calcification is increased in patients with COPD and associated with increased morbidity and mortality. Thorax 2014 [In press DOI: 10.1136/thoraxjnl-2012203151].

10 Hurst JR, Vestbo J, Anzueto A, et al. Susceptibility to exacerbation in chronic obstructive pulmonary disease. N Engl J Med 2010; 363: 1128-1138.

11 Kessler R, Partridge MR, Miravitlles M, et al. Symptom variability in patients with severe COPD: a pan-European cross-sectional study. Eur Respir J 2011; 37: 264-272.

12 Plato. Apology of Socrates. 399 BC.

13 Han MK, Agusti A, Calverley PM, et al. Chronic obstructive pulmonary disease phenotypes: the future of COPD. Am J Respir Crit Care Med 2010; 182: 598-604.

14 Agustí A, Celli B. Avoiding confusion in COPD: from risk factors to phenotypes to measures of disease characterisation. Eur Respir J 2011; 38: 749-751.

15 Burgel PR, Paillasseur JL, Caillaud D, et al. Clinical COPD phenotypes: a novel approach using principal component and cluster analyses. Eur Respir J 2010; 36: 531-539.

16 Schols AM, Broekhuizen R, Weling-Scheepers CA, et al. Body composition and mortality in chronic obstructive pulmonary disease. Am J Clin Nutr 2005; 82: 53-59.

17 Pinto-Plata VM, Cote C, Cabral H, et al. The 6-min walk distance: change over time and value as a predictor of survival in severe COPD. Eur Respir J 2004; 23: 28-33. 